\title{
Information And Communication Technologies And Aboriginal Peoples In Canada: Information Seeking, Community Building, And Access Challenges In Geographically And Socially Marginalized Populations
}

Kathryn M. Kimery, Saint Mary’s University - Halifax, Canada

Samad Amirkhalkhali, Saint Mary’s University - Halifax, Canada

\begin{abstract}
People are coming to rely on Information and Communications Technologies (ICT) to provide them with access to education, healthcare, and government and community services. This paper presents a brief introduction to Aboriginal populations in Canada and the current state of ICT access and adoption among these groups.
\end{abstract}

Keywords: internet; Aboriginal peoples; information and computer technology

\section{INTRODUCTION}

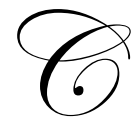

omputers and the digital networks that connect them represent a powerful tool to inform, educate, deliver services, entertain, and connect individuals across the globe. In Canada, policy-makers, business leaders, researchers, educators, and individuals have all come to recognize the often-times high cost of ICT as an investment in human capital development and future competitiveness.

A number of economic, technical, and social factors, however, influence how ICTs can be effectively employed to suit the needs, resources, and capacities of different population groups. The most common factors creating a barrier to ICT adoption in Canada include the cost for hardware and software, availability of effective and reliable communication connections, especially in rural areas, and the absence of required skills and computerrelated training (Statistics Canada, 2000). Cross-cultural research has also examined how differences in cultural beliefs or orientations can impact the way individuals perceive various characteristics of ICTs and how these perceptions influence intentions and abilities to adopt and adapt such technologies (e.g., Kimery \& Amirkhalkhali, 2007; Van Slyke, C., Belanger, F., \& Sridhar, V. (2005); Straub, Keil, \& Brenner, 1997). Most of the existing crosscultural research on ICT adoption and use has focused on differences between populations from distinct national cultures (for example, between China and Canada). Very little published research has focused on the special circumstances experienced by marginalized population groups, such as Aboriginal peoples in Canada, living as part of, yet spatial or culturally separate from, a larger, dominant national culture.

In Canada, various government initiatives are planned or are underway to increase the level of Internet connectivity for Aboriginal populations, including First Nations, Inuit, and Métis. Other efforts have been spearheaded internally by Aboriginal communities to enhance technical capacity and awareness and to promote Internet-based communication as a means of supporting the information, economic, and educational needs of their 
communities. While championing the drive to increase availability of ICT to Aboriginal communities, Aboriginal leaders have also expressed concern about the barriers to effective ICT adoption and the potential hazards posed to cultural identity and vitality should the technology be designed or deployed inappropriately.

This paper presents a brief introduction to Aboriginal populations in Canada and the current state of ICT access and adoption among these groups. This background contributes to a forthcoming comprehensive study of: 1) the impact of Aboriginal culture on perceptions and adoption of ICTs, 2) the role of ICTs in enhancing cultural revitalization, self-determination, and social capital among Aboriginal groups, and 3) specific challenges to be overcome or managed to more effectively and beneficially implement ICT in Aboriginal communities in Canada. It is expected that the results of this study can be used to help fulfill the "virtuous" intentions of ICT implementation to support the economic development and overall quality of life for Aboriginal people in Canada.

\section{ABORIGINAL PEOPLES IN CANADA}

"Aboriginal" is the term used in the Canadian Constitution Act of 1982 to describe the descendants of the original inhabitants of Canada. Three distinct ethnic groups are recognized as comprising Aboriginal peoples by the government of Canada: First Nations, Inuit, and Métis. First Nations ${ }^{1}$ are organized politically and socially into bands or governments, each with its own governing council. There are currently more than 630 recognized First Nations bands in Canada. First Nations members may live on lands specifically held for them by the government of Canada or may live off-reserve in rural areas or urban centers across Canada. The Inuit have traditionally occupied the arctic and sub-arctic regions of what is now Canada. The Inuit homeland in Canada includes portions of Labrador, Northern Quebec, and the territories of Nunavut, the Yukon, and the Northwest Territories. The Métis are descendents of North American Indian or Inuit and early European immigrants, largely French-Canadian traders or Scottish and British farmers. The Métis culture, language, and religion reflect syntheses of those brought together by their ancestors. The Métis have been recognized as a distinct group of Aboriginal people with rights and protections under the Constitution Act and subsequent court rulings (Aboriginal Canada Portal, 2004).

Based on census data collected in 2006, a total of 1,172,790 people self-identify as First Nations, Inuit, or Métis in $\mathrm{Canada}^{2}$, representing almost $4 \%$ of the total Canadian population. The number of Aboriginal people in Canada is growing much faster than the non-Aboriginal population. In 2006, the Aboriginal population had increased by $45 \%$ over that recorded in 1996. While a portion of this growth can be attributed to declining Aboriginal infant mortality rates and a birthrate that is 1.5 times that of non-Aboriginals, it is suggested by Statistics Canada that up to half of the growth may be the result of increased awareness of Aboriginal roots and willingness to self-identify as Aboriginal. In the 2006 census, 62\% of Aboriginal people in Canada identify themselves as First Nations, while another 30\% identify as Métis, and only 5\% as Inuit. The Aboriginal population is also relatively young, with a median age of 27 years compared to 40 years for non-Aboriginals in Canada (Statistics Canada, 2006).

Aboriginal people are living in all provinces of Canada, but the highest concentrations are in northern Canada and in the Prairie provinces. Aboriginals make up the vast majority of Nunavut inhabitants (85\%) and represent $51 \%$ of the population in the Northwest Territories and $25 \%$ of the population in the Yukon. They make up sizeable minorities (15\%) in both Manitoba and Saskatchewan. Despite these areas of high concentration, the largest absolute number of Aboriginal people lives in Ontario (242,495), although this represents only $2 \%$ of the total provincial population. While the absolute numbers and concentrations are relatively low, the highest growth is occurring in the eastern provinces, almost doubling between 2001 and 2006 in Nova Scotia (a 95\% increase). The 2006 census also clearly shows that Aboriginal people are becoming increasingly urban, with $54 \%$ living in census metropolitan areas or other urban centers. While this is still substantially below the $81 \%$ of non-Aboriginal people who are urban dwellers, it does reflect an increase of four percentage points from 2001. The city of Winnipeg in the province of Manitoba had the largest Aboriginal population in 2006 (68,380), Edmonton, Alberta, the second largest $(52,100)$, followed by Vancouver, British Columbia, $(40,310)$. The most concentrated Aboriginal populations in census metropolitan areas are in Saskatoon, Saskatchewan (9\% of the population), and Winnipeg (8\% of the population) (Statistics Canada, 2006). 
While widely recognized as a multi-cultural society, Canadians of non-European descent continue to have reduced access to economic power and privilege in Canada (Gosine, 2000). Specifically, Aboriginal peoples have been identified in the research literature as marginalized in Canada, in the sense that they tend to be distanced from the center of the dominant, European-derived, Canadian culture (Thiessen \& Looker, 2008). Distance from the cultural core is described as a combined function of spatial, social, and cultural separateness. Spatial distance from the core is derived from habitation patterns and, as a result, is greatest for those Aboriginal people living on reserves or in remote rural settlements. These same individuals are less likely to have regular and frequent social interaction with members and institutions of the cultural core than are their off-reserve and urbanized counterparts. Cultural distance reflects a divergence between the lifestyles, values, and belief system of a group and the dominant cultural core. In general, distance from the cultural core is related to blocked mobility (Porter, 1965) and reduced social and economic opportunities for members of the marginalized group. Geschwender and Guppy (1995) suggest that an "ethnic penalty" exists for marginalized populations that reduces the value of human capital investments, such as education and training.

Aboriginal peoples in Canada exhibit all of the socio-economic characteristics of marginalized populations. While health and social conditions have improved over time, Aboriginal peoples continue to experience higher rates of serious health problems (including diabetes, obesity, cancer, cardiovascular disease, infant mortality), mental health issues, and environment-related diseases than do non-Aboriginal Canadians. Higher rates of unemployment and poverty, substance abuse, sexual assault, and domestic violence are all documented, as well as higher rates of infant mortality and suicide, and a shorter life expectancy (Health Canada, 2000, Hurst \& Nader, 2006; Minore \& Katt, 2007; Public Health Agency of Canada, 2004). Aboriginal groups have a substantially lower level of educational attainment and are more likely to leave school without graduating from high school than other Canadians (Siggner \& Costa, 2005). There is a significantly earnings gap between Aboriginal and non-Aboriginal Canadians, a gap that is not eliminated when education or other human capital variables are controlled (Siggner \& Costa, 2005; Gosine, 2000).

It has been recognized, during the past two decades, that other ICT can be a useful tool for improving access to education, healthcare information, and community services, as well as to enhance interaction between Aboriginals and non-Aboriginals and build cultural connectivity between members of Aboriginal groups who may be geographically dispersed. In Canada, key barriers to Internet adoption have been identified as cost, access to computers or the Internet, and lack of skills or training (Statistics Canada, 2000). Extending ICT infrastructures to make the technology more accessible and less cost-prohibitive, providing skill development opportunities, and building online content that is meaningful and useful for Aboriginal peoples has become a priority. Federal and provincial governments, along with Aboriginal groups, have been working independently and in concert to make ICTs more available and useful for Aboriginal Canadians. Government programs, such as the Community Access Program (Industry Canada, 2010a), Broadband for Rural and Northern Development (Industry Canada, 2010b), Connect Yukon project (Yukon Health and Human Services, 2009), and the First Nations SchoolNet Network (Saskatchewan Regional Management Organization, 2010), have provided financial and technical support for expanded ICT distribution into rural and remote locations. The Aboriginal Canada Portal (http://aboriginalcanada.gc.ca), a collaborative effort of the federal government and six Aboriginal councils (Assembly of First Nations, Inuit Tapiriit Kanatami, Congress of Aboriginal Peoples, Métis National Council, Native Women's Association of Canada, and Council for the Advancement of Native Development Officers) provides a single online access point for content relevant to Aboriginal people in Canada. First Nations-driven initiatives, such as the First Nations Technology Council (http://fnbc.info/FNTC/) and the Kuh-ke-nah Network (http://www.knet.ca), have been working to promote ICT deployment, provide technical support, and build infrastructure for rural First Nations communities.

Based on a program of annual surveys of Aboriginal communities completed between 2000 and 2004 (Aboriginal Canada Portal, 2004), the efforts by government and Aboriginal groups to support ICT-based connectivity have had some success. In 2000, off-reserve Aboriginal people were as likely to use the Internet as other Canadians (50\% vs. 53\%). Like non-Aboriginal users, Aboriginal Internet users tended to be more urban, better-educated, and to earn higher annual salaries than Aboriginals who did not report use of the Internet. Compared to non-Aboriginal Internet users, Aboriginal users were less likely to have access to the Internet in their homes (56\% vs. $81 \%$ ), however, and were also less likely to use a computer at work (55\% vs. 68\%). The 2004 
"Report on Aboriginal Community Connectivity Infrastructure" (Aboriginal Canada Portal, 2004) reports that approximately $96 \%$ of Aboriginal communities surveyed (737 communities, in total) had some form of basic, tollfree Internet access in the community, with $20 \%$ of communities having high-speed Internet access. The vast majority of these communities (85\%) estimated, however, that less than half of the households in their communities had Internet access in their homes.

\section{FUTURE WORK}

This study is in its very early stages. Work continues to create a comprehensive understanding of the state of current ICT access and adoption among Aboriginal Canadians. From this foundation, specific research questions will be developed and addressed through archival data analysis and additional field research.

\section{AUTHORS INFORMATION}

Dr. Kathryn M. Kimery is Associate Professor of Computing and Information Systems at Saint Mary's University in Halifax, NS, Canada. Her research focuses on electronic commerce and social aspects of computing, and has been published in journals, including Journal of Business Research, Journal of Information Technology Theory and Application, and Journal of Electronic Commerce in Organizations, as well as in numerous refereed proceedings. E-mail: k.kimery@smu.ca

Dr. Samad Amirkhalkhali is Associate Professor of Management Science at Saint Mary's University. His publications include papers in journals, such as Empirical Economics, Southern Economic Journal, Canadian Journal of Economics, Economic Modeling, The Statistician (published by the Royal Statistical Society), and Journal of Statistical Computation and Simulation, and many refereed proceedings. E-mail: samad.amirkhalkhali@smu.ca

\section{NOTES}

${ }^{1}$ First Nations peoples are referred to in the Constitution Act, the earlier Indian Act of 1876, and subsequent amending legislation as "North American Indians". Although the term First Nations has no definition in Canadian legislation, the term "Indian" is considered a pejorative term by many. First Nations is the name adopted and recognized by most people in Canada and will be used to refer to Aboriginal people who are not Inuit or Métis in this paper.

${ }^{2}$ It is important to note that census enumeration has never been complete for Aboriginal peoples living on reserves and settlements in Canada, although the completion rate has been increasing steadily over the years. There were 22 incomplete enumerations of reserves or settlements in 2006 compared to 77 ten years before. Statistics Canada adjusts census data on Aboriginal populations in an attempt to improve its overall accuracy and uses only data from completely enumerated communities in calculations of population change.

\section{REFERENCES}

1. Aboriginal Canada Portal (2004) Report on Aboriginal Community Connectivity Infrastructure. Retrieved May 1,2010 at http://www.aboriginalcanada.gc.ca/acp/site.nsf/vDownload/connectivity2004report/\$file/2004ROAC.pdf

2. Geschwender, J.A., \& Guppy, N. (1995) Ethnicity, educational attainment, and earned income among Canadian-born men and women. Canadian Ethnic Studies, 27:67-84.

3. Gosine, K. (2000) Revisiting the notion of a 'recast' vertical mosaic in Canada: Does a post secondary education make a difference? Canadian Ethnic Studies, 32:89-110.

4. Graham, S. (2002) Bridging urban digital divides: Urban polarization and information and communications technologies (ICTs). Urban Studies, 39:33-56.

5. Health Canada (2000) First Nations, Inuit and Aboriginal Health: Statistical Profile on the Health of First Nations in Canada. Ottawa, ON: Health Canada. 
6. Hurst, S., \& Nader, P. (2006) Building community involvement in cross-cultural indigenous health programs. International Journal of Quality in Health Care, 18:294-298.

7. Industry Canada (2010a) Community Access Program (CAP). Retrieved May 1, 2010 from http://www.ic.gc.ca/eic/site/cap-pac.nsf/eng/home

8. Industry Canada (2010b) Broadband Canada: Connecting Rural Canadians. Retrieved May 1, 2010 from http://broadband.gc.ca

9. Kimery, K., \& Amirkhalkhali, S. (2007) Cultural differences in diffusion of innovation: A comparison of Japan and the United States. 2007 EABR (Business) \& ETLC (Teaching) Conference Proceedings, 1-11.

10. Minore, B. \& Katt, M. (2007) Aboriginal Health Care in Northern Ontario: Impacts of Self-Determination and Culture (Rep. No. 13).

11. Porter, J. (1965) The Vertical Mosaic: An Analysis of Social Class and Power in Canada. Toronto: University of Toronto Press.

12. Public Health Agency of Canada (2004) Aboriginal Peoples' Roundtable Report. Ottawa, ON: Public Health Agency of Canada.

13. Saskatchewan Regional Management Organization (2010) First Nations Schoolnet. Retrieved May 1, 2010 from http://www.firstnationsnt.ca/index.php

14. Siggner, A. J., \& Costa, R. (2005) Aboriginal Conditions in Census Metropolitan Areas, 1981-2001. Trends and Conditions in Census Metropolitan Areas, (Catalogue No. 89-613-MIE, No. 008). Ottawa: Statistics Canada.

15. Straub, D., Keil, M., \& Brenner, W. (1997) Testing the technology acceptance model across cultures: A three country study. Information \& Management, 33:1-11.

16. Statistics Canada (2000) General Social Survey Cycle 14: Access to and Use of Information Communication_Technology. Retrieved May 1, 2010 from http:/www.statcan.gc.ca/cgibin/imdb/psSV.p1 ? Function=getSurvey $\&$ SDDS $=4505 \&$ Lang=eng $\& \mathrm{db}=\mathrm{imdb} \& \mathrm{adm}=8 \& \mathrm{dis}=2$

17. Statistics Canada (2006) Aboriginal Peoples Survey, 2006: Inuit, Metis and First Nations, 2006 Census. Retrieved May 1, 2010 from http://www12.statcan.ca/census-recensement/2006/as-sa/970558/pl-eng.cfm

18. Thiessen, V., \& Looker, E. D. (2008) Cultural centrality and information and communication technology among Canadian youth. Canadian Journal of Sociology, 33(2):311-336.

19. Van Slyke, C., Belanger, F., \& Sridhar, V. (2005) A comparison of American and Indian consumers' perceptions of electronic commerce. Information Resources Management Journal, 18(2):24-40.

20. Yukon Health and Social Services (2009) Yukon at the Forefront of E-health Expansion, News Release. Retrieved May 1, 2010 from http://www.hss.gov.yk.ca/news/09-256.php 


\section{NOTES}

